\title{
On the Structural and Magnetic Properties of $\mathrm{Cr}_{1-t} \mathrm{Fe}_{t} \mathrm{P}$, $\mathrm{Mn}_{1-t} \mathrm{Co}_{t} \mathrm{P}$ and $\mathrm{Fe}_{1-t} \mathrm{Co}_{t} \mathrm{P}$
}

\author{
KARI SELTE, LEIF BIRKELAND and ARNE KJEKSHUS
}

Kjemisk Institutt, Universitetet i Oslo, Blindern, Oslo 3, Norway

The pseudo-binary $\mathrm{CrP}-\mathrm{FeP}, \mathrm{MnP}-\mathrm{CoP}$, and $\mathrm{FeP}-\mathrm{CoP}$ systems have been investigated by $\mathrm{X}$-ray diffraction and magnetic susceptibility measurements. The three systems show complete solid solu-

a

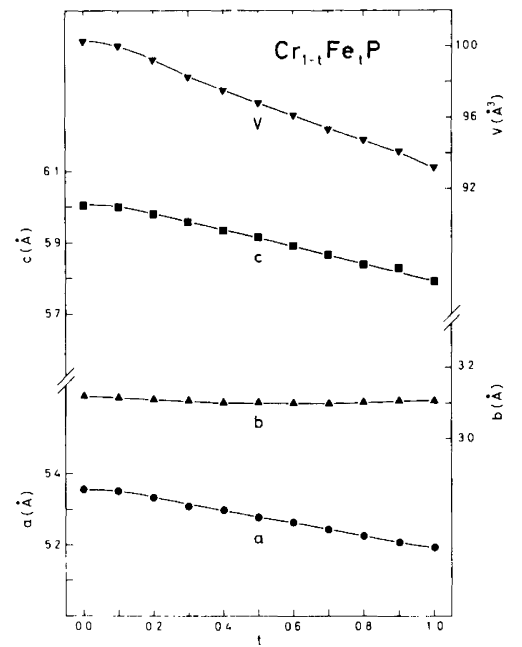

c

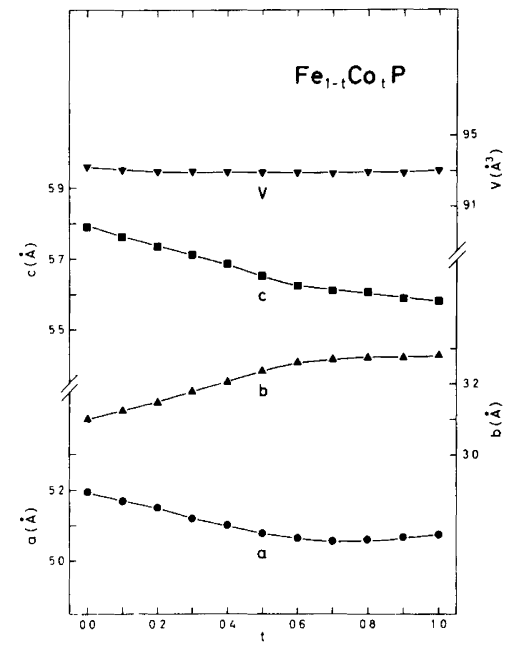

bility with $\mathrm{MnP}$ type structure and random distribution of the metal atoms. The paramagnetic susceptibilities follow the Curie-Weiss Law only for samples rich in $\mathrm{MnP}$.

b

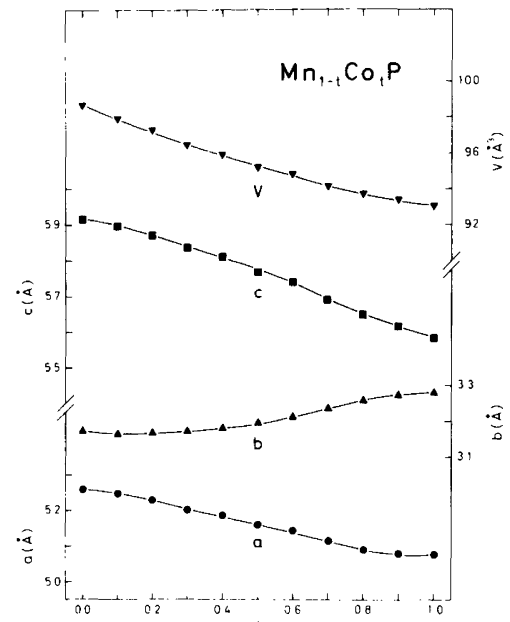

Fig. 1. Room temperature unit cell dimensions of (a) $\mathrm{Cr}_{1-t} \mathrm{Fe}_{t} \mathrm{P}$, (b) $\mathrm{Mn}_{1-t} \mathrm{Co}_{t} \mathrm{P}$, and (c) $\mathrm{Fe}_{1-t} \mathrm{Co}_{t} \mathrm{P}$ as functions of $t$. 
a

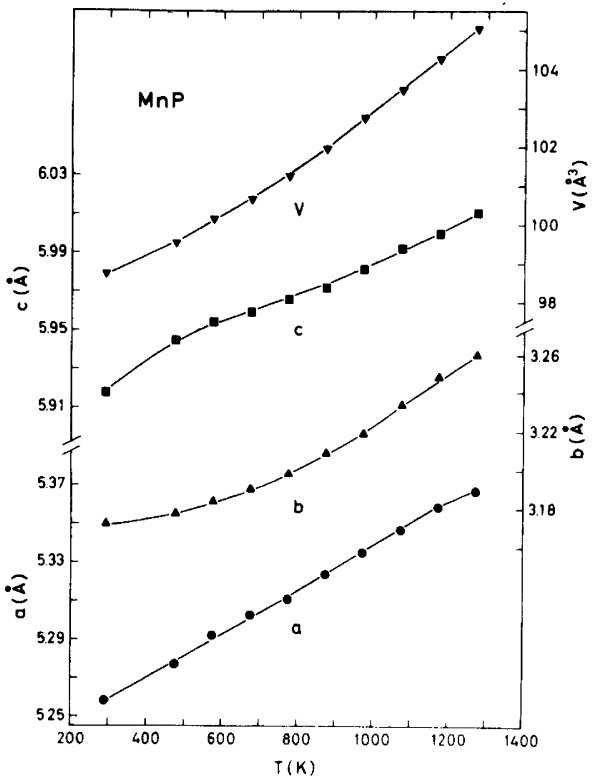

c

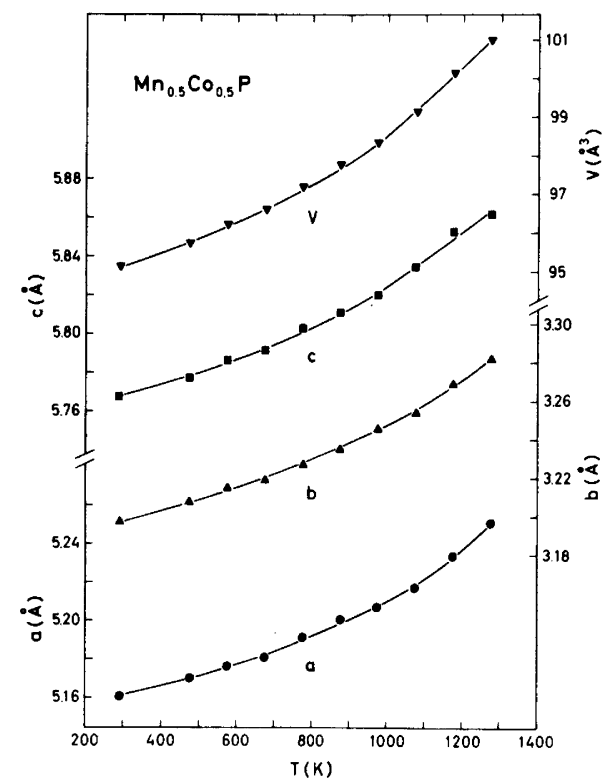

b

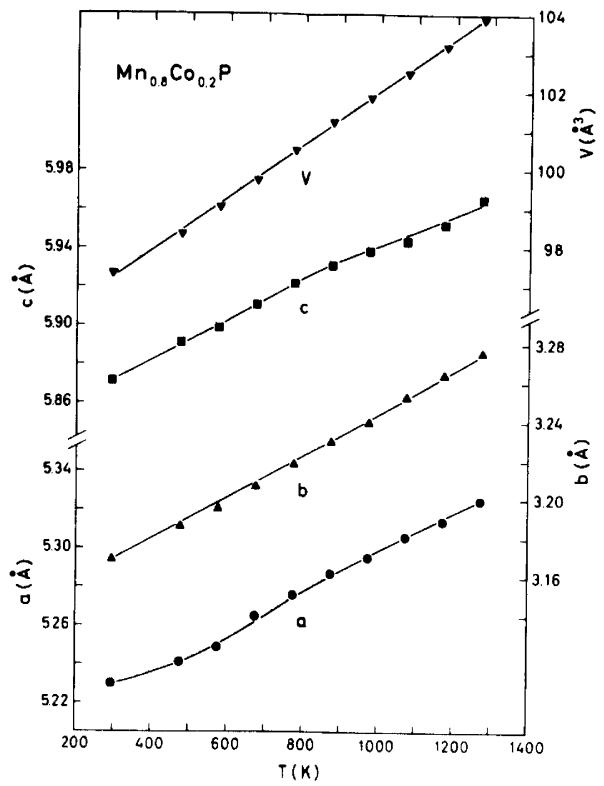

d

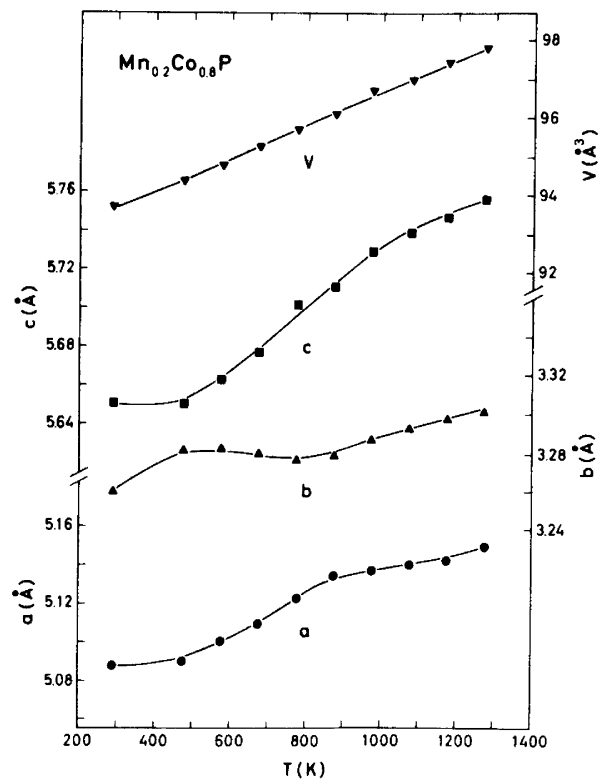

Fig. 2. Unit cell dimensions of (a) $\mathrm{MnP}$, (b) $\mathrm{Mn}_{0.8} \mathrm{Co}_{0.2} \mathrm{P}$, (c) $\mathrm{Mn}_{0.5} \mathrm{Co}_{0.5} \mathrm{P}$, (d) $\mathrm{Mn}_{0.2} \mathrm{Co}_{0.8} \mathrm{P}$, (e) FeP,

The mono-phosphides and -arsenides of the transition metals $\mathrm{Cr}, \mathrm{Mn}, \mathrm{Fe}$, and Co take the MnP type structure. The structural and magnetic properties of the mono-arsenides (both binary and pseudobinary) have been extensively studied at this Institute and are now well characterized. The corresponding properties of the mono-phosphides have been given less attention. The behaviour of the binary compounds is mainly disclosed,,${ }^{1-13}$ whereas only a few characteristics have been reported for the pseudo- 
e

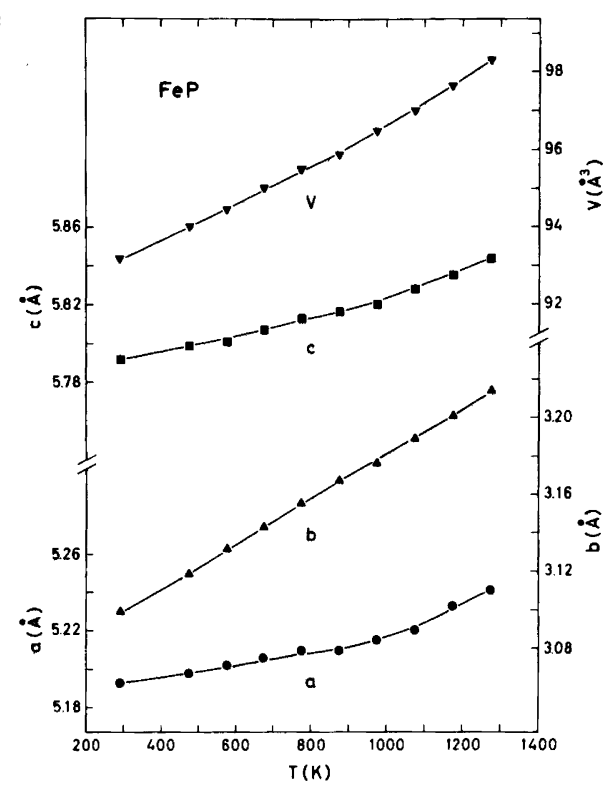

g

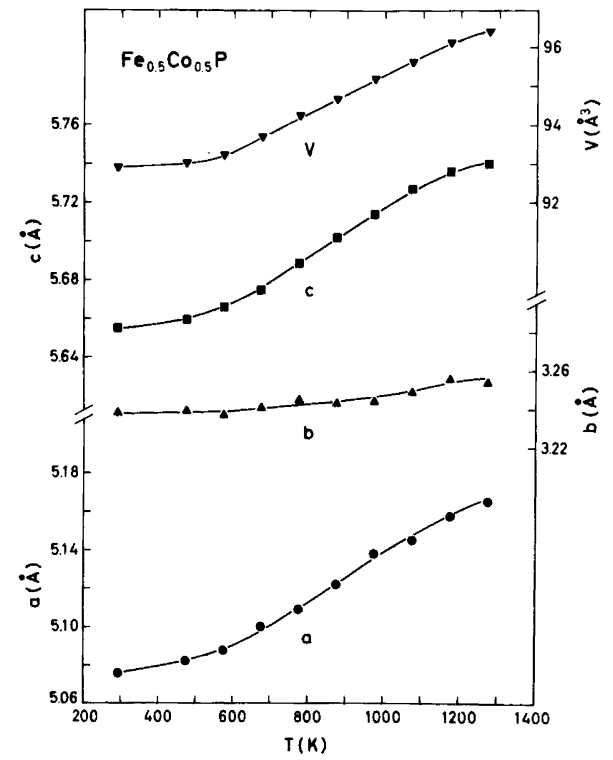

f

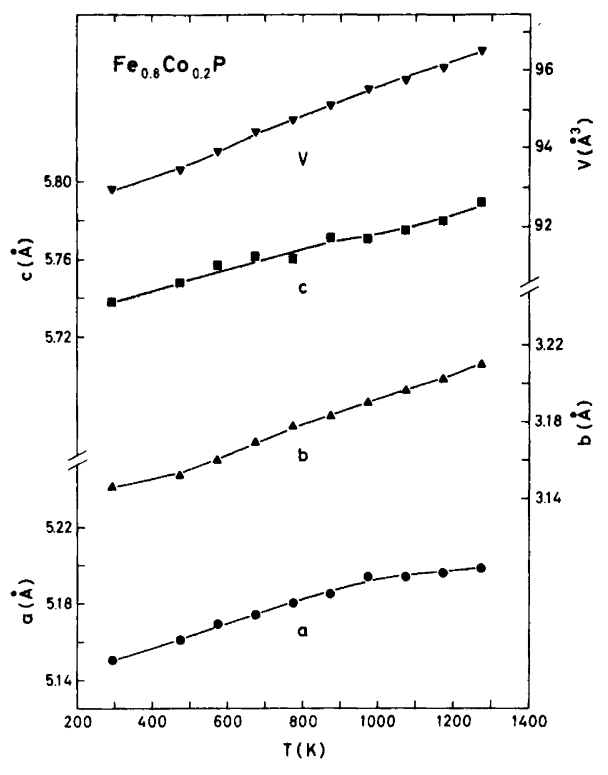

$\mathrm{h}$

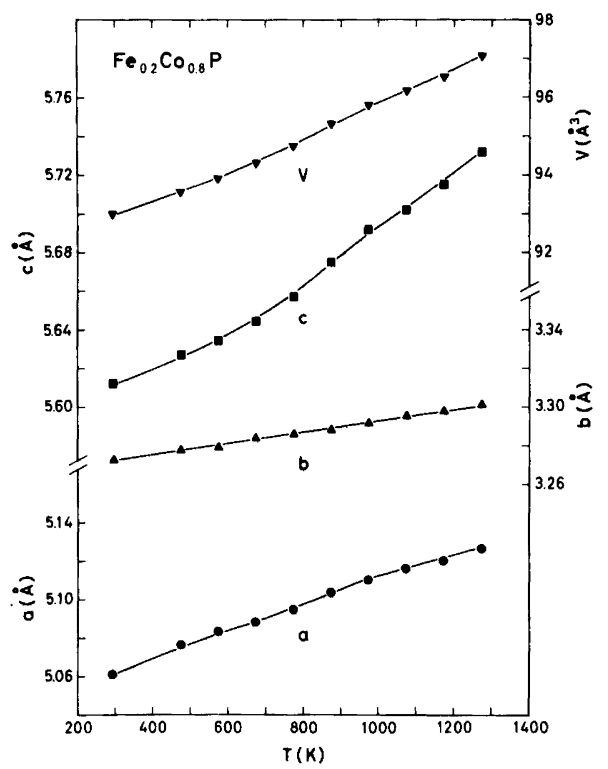

(f) $\mathrm{Fe}_{0.8} \mathrm{Co}_{0.2} \mathrm{P}$, (g) $\mathrm{Fe}_{0.5} \mathrm{Co}_{0.5} \mathrm{P}$, and (h) $\mathrm{Fe}_{0.2} \mathrm{Co}_{0.8} \mathrm{P}$ as functions of temperature.

binary mono-phosphides. ${ }^{14-18}$ As a continuation of our programme on $\mathrm{MnP}$ type phases, attention has now been focussed on these ternary phosphides.

\section{EXPERIMENTAL}

Samples were made from $99.99 \% \mathrm{Mn}$ and $\mathrm{Fe}$, $99.99+\%$ Co (Johnson, Matthey \& Co.; crushed $\mathrm{Mn}$ flakes, turnings from rods of $\mathrm{Fe}$ and $\mathrm{Co}$ ), $99.999 \%$ crushed Cr flakes and red P (Koch-Light

Acta Chem. Scand. A 32 (1978) No. 8 
Laboratories). Binary samples of $\mathrm{FeP}$ and $\mathrm{CrP}$ were prepared as described in Refs. 10 and 11. CoP was obtained after two heat treatments, one at $1000{ }^{\circ} \mathrm{C}$ for $2 \mathrm{~d}$, followed by $1 \mathrm{~d}$ at $1200{ }^{\circ} \mathrm{C}$ and $2 \mathrm{~d}$ at $1000^{\circ} \mathrm{C}$. $\mathrm{MnP}$ was prepared by a first heat treatment at $650{ }^{\circ} \mathrm{C}$ for 1 week, the second at $1100{ }^{\circ} \mathrm{C}$ for $1 \mathrm{~h}$ followed by slow cooling to $600{ }^{\circ} \mathrm{C}$. Ternary samples were made from the binary compounds by one heat treatment at $1000{ }^{\circ} \mathrm{C}$ for $2 \mathrm{~d}$ followed by another of $1 \mathrm{~d}$ at $1000{ }^{\circ} \mathrm{C}, 1$ week at $850{ }^{\circ} \mathrm{C}$, slow cooling to a

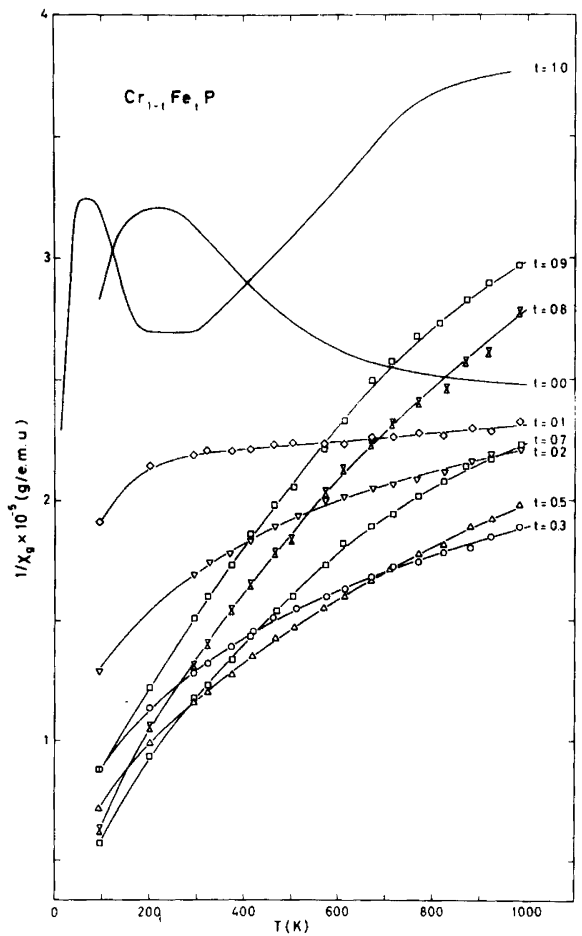

$600{ }^{\circ} \mathrm{C}$ and then quenching. The experimental details concerning $\mathrm{X}$-ray diffraction and magnetic susceptibility measurements have been reported earlier. ${ }^{19}$

\section{RESULTS}

(i) Homogeneity ranges and atomic arrangement. Isothermal cross-sections of $\mathrm{Cr}_{1-t} \mathrm{Fe}_{t} \mathrm{P}, \mathrm{Mn}_{1-t} \mathrm{Co}_{t} \mathrm{P}$, and $\mathrm{Fe}_{1-t} \mathrm{Co}_{t} \mathrm{P}$, as derived for samples quenched from $600{ }^{\circ} \mathrm{C}$, show (Fig. 1) that these systems exhibit complete solid solubility. Only ternary samples with metal/non-metal atomic ratios equal to 1.00 have
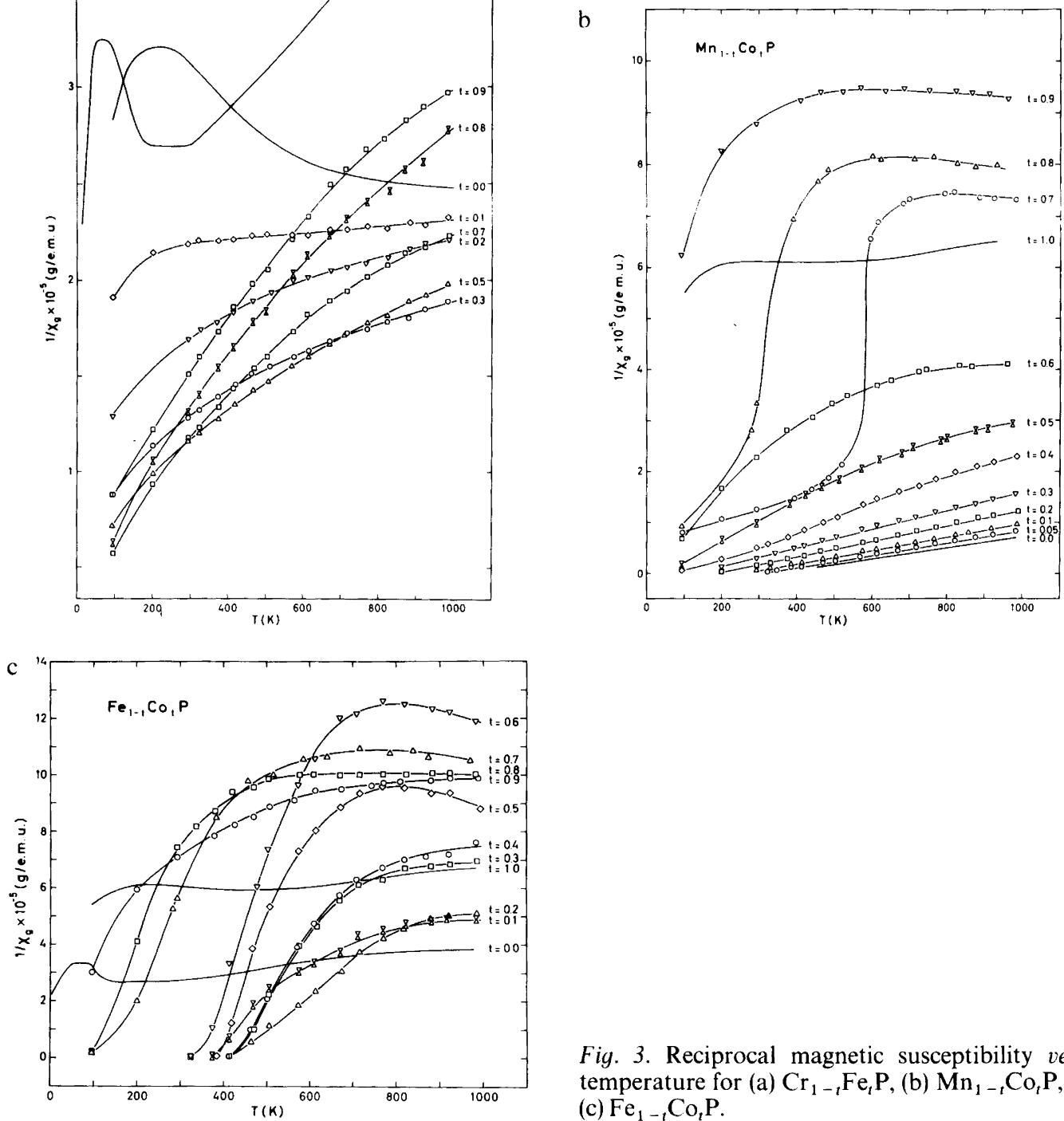

Fig. 3. Reciprocal magnetic susceptibility versus temperature for (a) $\mathrm{Cr}_{1-t} \mathrm{Fe}_{t} \mathrm{P}$, (b) $\mathrm{Mn}_{1-t} \mathrm{Co}_{t} \mathrm{P}$, and (c) $\mathrm{Fe}_{1-t} \mathrm{Co}_{t} \mathrm{P}$. 
Table 1. Curie constant $(\theta)$, paramagnetic moment $\left(\mu_{\mathrm{P}}=\sqrt{8 C_{\mathrm{M}}}\right)$, and number of unpaired electrons $\left(n=2 S_{T}\right)$ for $\mathrm{Mn}_{1-t} \mathrm{Co}_{t} \mathrm{P}$ samples which fulfil CurieWeiss Law.

\begin{tabular}{llll}
\hline$t$ & $\theta(\mathrm{K})$ & $\mu_{\mathrm{P}}\left(\mu_{\mathrm{B}}\right)$ & $2 S_{T}$ \\
\hline 0.00 & $310 \pm 10$ & $2.6 \pm 0.1$ & $1.8 \pm 0.1$ \\
0.05 & $300 \pm 10$ & $2.4 \pm 0.1$ & $1.6 \pm 0.1$ \\
0.10 & $255 \pm 10$ & $2.2 \pm 0.1$ & $1.5 \pm 0.1$ \\
0.20 & $190 \pm 10$ & $2.1 \pm 0.1$ & $1.3 \pm 0.1$ \\
0.30 & $130 \pm 15$ & $1.9 \pm 0.1$ & $1.2 \pm 0.1$ \\
0.40 & $80 \pm 20$ & $1.7 \pm 0.1$ & $1.0 \pm 0.1$ \\
\hline
\end{tabular}

been examined. The diffraction data show that $\mathrm{Cr}_{1-t} \mathrm{Fe}_{t} \mathrm{P}, \mathrm{Mn}_{1-t} \mathrm{Co}_{t} \mathrm{P}$, and $\mathrm{Fe}_{1-t} \mathrm{Co}_{t} \mathrm{P}(0 \leq t \leq 1)$ take the orthorhombic MnP type structure with random distribution of the two kinds of metal atoms. This applies also to samples of approximate composition $\mathrm{Mn}_{0.2} \mathrm{Co}_{0.8} \mathrm{P}$ and $\mathrm{Fe}_{0.4} \mathrm{Co}_{0.6} \mathrm{P}$ for which the axial ratio $c / b$ is $\sqrt{3}$ and hexagonal symmetry (e.g., NiAs type structure) could have been a possibility. This confirms the findings of Rundqvist. ${ }^{14}$

A second or higher order transition to the NiAs type structure has been detected above room temperature for many binary and ternary MnP type arsenide phases. ${ }^{20,21}$ However, the high temperature, $\mathrm{X}$-ray diffraction measurements on $\mathrm{Mn}_{1-t} \mathrm{Co}_{t} \mathrm{P}$ and $\mathrm{Fe}_{1-t} \mathrm{Co}_{t} \mathrm{P}$ samples with $t=0,0.2,0.5$, and 0.8 (results for $\mathrm{CrP}$ and $\mathrm{CoP}$ being presented earlier ${ }^{20}$ ) show no such transition, as demonstrated by the results given in Fig. 2.

(ii) Magnetic susceptibility. The temperature characteristics of the reciprocal magnetic susceptibility show systematic variation with the composition parameter $t$ for $\mathrm{Cr}_{1-t} \mathrm{Fe}_{t} \mathrm{P}, \mathrm{Mn}_{1-t} \mathrm{Co}_{t} \mathrm{P}$, and $\mathrm{Fe}_{1-t} \mathrm{Co}_{t} \mathrm{P}$ (Fig. 3). No signs of ferri- or ferromagnetic impurities were found. The $\chi^{-1}(\mathrm{~T})$ curves for $\mathrm{Cr}_{1-t} \mathrm{Fe}_{t} \mathrm{P}$ and $\mathrm{Fe}_{1-t} \mathrm{Co}_{t} \mathrm{P}$ are generally nonlinear and convex towards the temperature axis. The same applies to $\mathrm{Mn}_{1-t} \mathrm{Co}_{t} \mathrm{P}$ for $t>0.4 . \chi^{-1}(\mathrm{~T})$ is, on the other hand, linear to a very good approximation for $0 \leq t \leq 0.4$. The Curie-Weiss Law is accordingly fulfilled, and values for the Curie constant, paramagnetic moment, and number of unpaired electrons according to the "spin only" approximation are listed in Table 1. With decreasing content of $\mathrm{Mn}$ there is a gradual reduction in these magnetic parameters. The present findings for $\mathrm{Mn}_{1-t} \mathrm{Co}_{t} \mathrm{P}$ concur with those of Huber and Ridgley ${ }^{1}$ for the paramagnetic state of $\mathrm{MnP}$, and are also reasonably consistent with data (cf., e.g., Refs. 1 and 4) on its ferromagnetic state. It may be worth noting that $\mathrm{MnP}$ itself and its $\mathrm{Mn}$ rich ternary derivatives are the only phases with MnP type structure hitherto that fulfil the Curie-Weiss Law over an appreciable temperature interval.

Acknowledgement. This work has received financial support from The Norwegian Research Council for Science and the Humanities.

\section{REFERENCES}

1. Huber, E. E. and Ridgley, D. H. Phys. Rev. 135 (1964) A1033.

2. Rundqvist, S. and Nawapong, P. C. Acta Chem. Scand. 19 (1965) 1006.

3. Komatsubara, T., Kinoshita, K. and Hirahara, E. J. Phys. Soc. Jpn. 20 (1965) 2036.

4. Felcher, G. P. J. Appl. Phys. 37 (1966) 1056.

5. Forsyth, J. B., Pickart, S. J. and Brown, P. J. Proc. Phys. Soc. 88 (1966) 333.

6. Bellavance, D., Vlasse, M., Morris, B. and Wold, A. J. Solid State Chem. 1 (1969) 82.

7. Ishikawa, Y., Komatsubara, T. and Hirahara, E. Phys. Rev. Lett. 23 (1969) 532.

8. Wäppling, R., Häggström, L., Rundqvist, S and Karlsson, E. J. Solid State Chem. 3 (1971) 276.

9. Felcher, G. P., Smith, F. A., Bellavance, D. and Wold, A. Phys. Rev. B 3 (1971) 3046.

10. Selte, K. and Kjekshus, A. Acta Chem. Scand. $26(1972) 1276$.

11. Selte, K., Kjekshus, A. and Andresen, A. F. Acta Chem. Scand. 26 (1972) 4188.

12. Selte, K., Hjersing, H., Kjekshus, A., Andresen, A. F. and Fischer, P. Acta Chem. Scand. A 29 (1975) 695.

13. Westerstrandh, B., Lundgren, L., Gäfvert, U. and Karlsson, B. Phys. Scr. 15 (1977) 276.

14. Rundqvist, S. Acta Chem. Scand. 16 (1962) 287.

15. Roger, A. and Fruchart, R. C.R. Acad. Sci. Ser. C 264 (1967) 508.

16. Bonnerot, J., Fruchart, R. and Roger, A. Phys. Lett. A 26 (1968) 536.

17. Sénateur, J.-P., Roger, A., Fruchart, R. and Chappert, J. C.R. Acad. Sci. Ser. C 269 (1969) 1385 .

18. Maeda, Y. and Takashima, Y. J. Inorg. Nucl. Chem. 35 (1973) 1219.

19. Selte, K., Kjekshus, A. and Andresen, A. F. Acta Chem. Scand. 26 (1972) 3101.

20. Selte, K. and Kjekshus, A. Acta Chem. Scand. 27 (1973) 3195.

21. Selte, K., Kjekshus, A., Andresen, A. F. and Zięba, A. J. Phys. Chem. Solids 38 (1977) 719.

Received April 18, 1978. 